\title{
What educational leaders should know about social media, collaboration and doctoral learning
}

\author{
Karen Johnson ${ }^{\mathrm{a}}$, J. Medgar Roberts ${ }^{\mathrm{b}}$, Mary W. Stout ${ }^{\mathrm{c}}$, Michelle Susberry Hill ${ }^{\mathrm{d}}$, Lisa \\ Wells ${ }^{\mathrm{e}}$
}

\author{
${ }^{a}$ University of Phoenix, USA, kjohnsonil@email.phoenix.edu, ORCID 0000-0002-8773-6402 \\ ${ }^{b}$ University of Phoenix, USA,dr.medgar.roberts@gmail.com,ORCID 0000-0003-1700-4414 \\ ${ }^{c}$ University of Phoenix, USA, stoutmw@email.phoenix.edu, ORCID 0000-0002-7147-4444 \\ ${ }^{d}$ University of Phoenix, USA, chelle638@email.phoenix.edu, ORCID 0000-0003-4127-8757 \\ ${ }^{e}$ University of Phoenix, USA, dr.lisa.wells@gmail.com, ORCID 0000-0002-8559-720X
}

\begin{abstract}
In a global society where knowledge, degrees, and credentials cross international borders, understanding what and how doctoral students think and communicate about learning is relevant to educational leadership. An implication could be in creating new solutions to the age-old problem of students completing coursework but not a dissertation, and therefore, not graduating. United States doctoral students are taking advantage of social media platforms to create, develop, or enhance Personal Learning Networks (PLN). A team of researchers using a qualitative research methodology studied both the views and experiences of nine doctoral students, who were members of a closed Facebook group created specifically as a PLN. The results of the research study confirmed that the students use social media for academic and personal communication, emotional support, and direction through the dissertation stage of doctoral studies. Thematic results concluded that the participants sought help with questions and answers about research, guidance on the Institutional Review Board (IRB) process, and celebrating achievements. Trust was also a significant factor in ensuring the completion of dissertations. The results provide educational leaders useful information and insight into the impact of social media on teaching, research, culture, and learning environmental designs.
\end{abstract}

Keywords: doctoral students, educational leadership, personal learning networks (PLN), qualitative, social media

\section{Introduction}

One of the common complaints regarding doctoral studies in general, and specifically online, is the loneliness that goes along with doctoral level research inquiry (Inman \& Silverstein, 2003). The dissertation process requires individual researchers to study a problem in a specific context that no one else has studied (Inman \& Silverstein, 2003). The nature of doctoral research has two inherent characteristics: (a) the doctoral student works alone for long stretches of time with few people who understand the mental, emotional, and sometimes physical stress that accompany the doctoral pursuit (Autry \& Carter, 2015), and (b) doctoral students have little access to networks of other doctoral students pursuing similar courses of study. The students are denied the conversational give and take Vygotsky isolated as essential to a meaningful learning process (Inman \& Silverstein, 2003). In many cases, the developing problems create a delay in the growth of the learner beyond their current level of proficiency to their maximum proficiency-their zone of proximal development (Harding-Dekum, Hamilton, \& Loyd, 2012).

While doctoral students struggle in isolation, adults are increasingly using and adapting to social media, such as Facebook, Twitter, Instagram, LinkedIn, and others. The trend is evident in random observations among doctoral learners online. In the United States, doctoral students are initiating connections through social media to create, develop, or enhance Personal Learning Networks (PLN) (Bennett \& Folley, 2014). Martindale and Dowdy (2010) described PLNs as a "manifestation of a learner's informal learning processes via the Web" (p. 177). Students reach out beyond university instruction into self-organized social media environments. For example, students using Facebook, Twitter, Instagram, and LinkedIn share writing assignment information and helpful hints. The students post about 
academic activities, sharing experiences from inside and outside the classroom, and perhaps most interestingly, sharing advice.

Interest in why and how doctoral students use social media for communication or to complete dissertations has not been a frequently researched topic. The limited body of research is in need of supplementation, and researchers propose that online social media communities need to be analyzed for why some students complete coursework but are not completing dissertations, despite the multiple resources that are available (Andrews, 2016; Berger, 2015; Hilscher, 2013; Kaufhold, 2017; Lindsay, 2015; Satariyan et al., 2015). Therefore, conducting an exploratory, qualitative content analysis research study to discover how and why doctoral students are reaching out on social media to enhance learning experiences is useful.

\section{Significance of the Study}

In a global society where knowledge, degrees, and credentials cross international borders, understanding what and how students think and communicate about learning becomes relevant. By addressing why doctoral students are seeking out others on social media carries a potential for educators to assist in finding PLNs, reaching out to the students in the PLNs, and helping students finish dissertations. The implication for leadership is in creating new solutions to the ageold problem of students who complete coursework but not a dissertation, and therefore, not graduating.

\section{Research Questions}

To assist educators' understanding of how doctoral students use social media to proceed through the doctoral process, an overarching research question and two sub-questions guided the research.

The overarching research question was:

- RQ. How are students using social media for communication?

The two sub-questions guiding the research were:

- SQ1. How are doctoral students using social media and the relationships formed to avoid feelings of isolation and disconnectedness?

- SQ2. How is social media helping students to proceed through their doctoral programs?

\section{Literature review}

Since the 1980s, the advancement of technology, communication, and social media has changed the way people and businesses communicate. ICT Facts and Figures reported that 70 percent of the world's youth were on the Internet in 2017 (Sanou, 2017). The majority of new users come from social media websites. Harvard Law Professor, Yochai Benkler, once pointed out that "What we see now is the emergence of more effective collective action practices that are decentralized but do not rely on either the price system or a managerial structure for coordination" (Suny-Levin Institute, 2013, pp. 28-29). In education, the decentralized structure that social media supports allows students access to niche-specific communities that provide students, faculty, and educational leaders an opportunity to find others who are experiencing similar life or professional needs.

\section{Growth of Social Media}

Globalization has accelerated change and encouraged technological innovations on a daily basis. The pace is rapid. Many people feel behind the times, and regularly purchase new devices or update services. On average, individuals purchase four or more devices and use two or three to access the Internet (De Argaez, 2017). Technology has created new jobs, innovations, and networking sites that allow individuals to connect globally. From 2012 to 2016 , Pew researchers found that the use of social media among adults continued to increase (Greenwood, Perrin, \& Duggan, 2017). The following figure illustrates the different trends among the various social media platforms identified by the Pew researchers. 
What educational leaders should know about social media, collaboration and doctoral learning

Johnson, Medgar Roberts, Stout, Susberry Hill, Wells

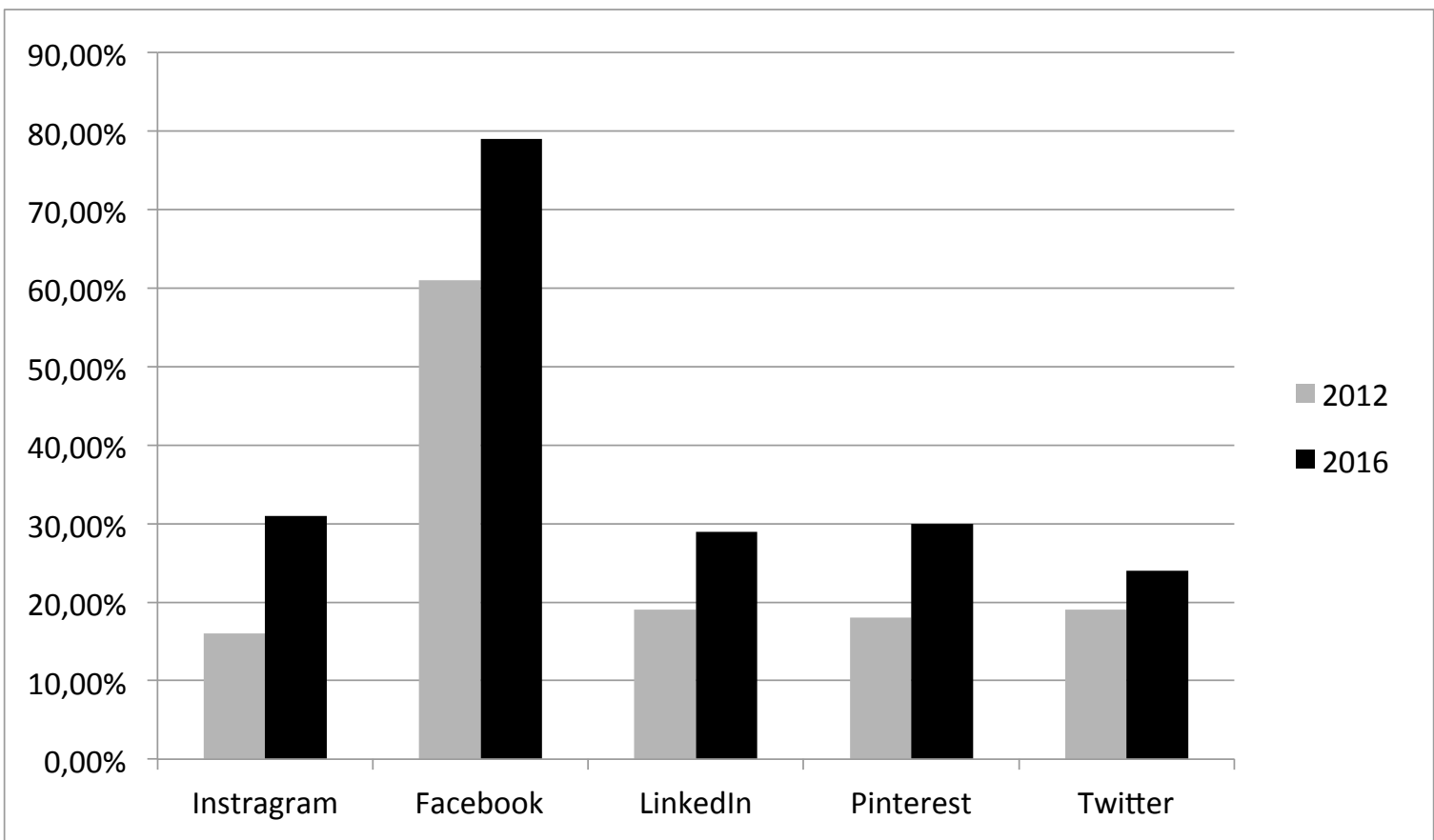

Figure 1. Social Media Timeline (Researcher generated). The figure illustrates the continuing growth of favourite social media sites between 2012 and 2016 as identified by Pew Research.

\section{Method and Design}

Since data collected in the form of textual narrative gives a voice to research participants, a qualitative research approach and content analysis design were suitable for the purpose of analysis of social media participation (Kuckartz, 2014; Merriam \& Tisdell, 2016). The exploratory content of analysis design is also appropriate as the focus is on human communication through contextual data taken from Facebook (Babbie, 2013). Few studies existed about doctoral students using Facebook as a PLN, and a systematic exploratory design was needed that provided documentation so that others might replicate the research (Babbie, 2013).

Five researchers with practitioner EdD degrees and extensive work in the field of education selected the Path to Dissertation (PtD) Facebook closed group for research. The researchers, who were not already members of PtD, joined the group to see and have access to the original research text. The researchers did not tell participants about the research until after the dates of data collection, because they did not want to interfere with the online dialogue that would become data or introduce any bias. Additionally, the participatory approach allowed for respondents to be truthful in answering questions, because the doctoral candidates knew the researchers were once in the same situation (ZuberSkerritt, 2015).

\section{Population and Sampling Frame}

The population is any student using a social media doctoral site as s PLN. Sampling frame included doctoral students using the PtD closed Facebook group. On the PtD homepage, the group's welcoming message said that the group "invites humor and insights (and frustrations) regarding the dissertation process" (Path to Dissertation Facebook Page, 2016). According to Facebook policy statements, anyone on Facebook can find the group and see the names of members while only group members can see posts and comments. The adult students in PtD were current or previously enrolled doctoral candidates, and they used social media to discuss experiences and attitudes toward online learning programs. The Facebook group had no voluntary association with a college or university and was open to all college and university doctoral students. Members were granted membership to the group by the group administrator or another member. Members used the platform to develop a Personal Learning Network (PLN).

The process of convenience sampling was used to identify participants for the study (Merriam \& Tisdell, 2016). Evaluation of members' posts required a content analysis (Babbie, 2013) for each of the original posts by individuals over a 10-month period. Each of the five members of the research team rated the posts to determine which would contribute to the purpose of the study (Salmons, 2016). After the end date, the research team independently rated the quality of the posts based on how well the information might contribute to the study. Choices for the ratings were as follows: 
1. Adds nothing substantive to the discussion,

2. Restates/agrees with another post,

3. Discusses minimally essential issues to dissertation completion or student well-being,

4. Expresses some ideas toward dissertation completion and student well-being, and

5. Greatly advances ideas toward dissertation completion and student well-being.

All PtD members, who scored an average of 3 or higher on a 1-5 scale for posts, were invited to participate in the research study.

Since the PtD students assumed confidentiality when posting in the closed Facebook group, informed consent forms with recruitment letters were sent to each group member that met the research criteria for the study. Nine students returned the informed consent forms and agreed to participate in the study. All participation was voluntary. Institutional Research Board (IRB) approval was acquired before contacting students to ensure proper interaction with participants.

\section{Materials and Instruments}

The materials and instrumentations used in the current research study included: (a) data collection from the Facebook closed group called Path to Dissertation or PtD, where doctoral students posted discussions, and researchers viewed the discussions, and (b) data analysis using NVivo Pro 11 for content analysis, word frequency, and theme development (Bazeley \& Jackson, 2013). According to Babbie (2013), both inductive and deductive procedures are used when using NVivo Pro 11 and constitute the basis for analyses. Content analysis involved deductive analysis by looking at the insight, expectations, and reflection of researchers for meaning based on general principles. The development of principles from observations based on word frequencies and themes from NVivo Pro 11 constituted the inductive model.

\section{Data Collection and Analysis Procedures}

Once potential participants were identified by the post-rating process, a request was sent through Facebook private messaging to individuals that scored a three or above for posts asking the PtD member to participate. Nine candidates responded with signed Informed Consent forms. Students clarified reactions, feelings, and interpretations in a voluntary follow-up interview, and participants did a process of member checking over the interview transcripts (Merriam \& Tisdale, 2016; Salmon 2016). The researchers then imported the interview transcriptions into Word or Excel spreadsheets.

The data from both the PtD ratings from an Excel spreadsheet and the interview transcripts (Saldana, 2016) were coded into NVivo Pro 11. The objective of data analysis coding was to reduce material while maintaining content and meaning. Mayring (2000) identified several analysis steps that included: (a) reduction (summarizing or inductive category formation), (b) explication (narrower and broader contextual analysis), (c) structuring (nominal and ordinal deductive category assignment), and (d) mixed (content structuring to pick themes, type analysis, and parallel forms). After summarizing the data, the researchers used the manifest system of coding in NVivo Pro 11 by looking for multiple occurrences of keywords (QSR International, 2017). For the first iteration of coding, the researchers developed a list of multiple words. For the second iteration of coding, the researchers chose the keywords or themes that were most relevant to the research. According to Chenail (2012), inspecting the frequencies of words in transcripts is not analysis, so by importing data into the NVivo Pro 11 software program, additional data emerged from the themes. Then a process of segregating tree nodes refined the extracted themes. According to Hamzah et al. (2013) organizing information into tree nodes helps with analyzing findings. The triangulation through multiple data sources and researcher expertise provided trustworthiness and dependability of the results.

\section{Findings}

The purpose of researching doctoral students' social media habits was to add to the general knowledge and understanding of how doctoral students use social media as the students proceed through doctoral programs. Using a qualitative research method was an appropriate method for the research purpose. The results included twenty-one frequency words and twelve themes.

The themes confirmed students were using social media for communication, support, and direction from other students to complete dissertations. Results included instances of students helping with questions and answers about conducting research, guidance about the IRB process, and helping to celebrate achievements. However, trust emerged as a factor in the success or failure of members completing dissertations. Some participants expressed frustration with answers to critical questions from instructors, advisors, or even members within the PtD group. The implication was that the doctoral students are searching for gainful information and insight that lead to the students' development and confidence as academics. 


\section{Word Frequency Results}

Data analysis began with organizing data from the PtD Facebook posts. A word frequency count in NVivo Pro 11 on posts from nine participants identified whose posts met the criteria for inclusion. The frequency count (QSR International, 2017) showed the top 21 words were (in order of frequency) social, media, doctoral, support, Facebook, group, emotional, dissertation, explain, process, student, describe, education, network, Phoenix, used, university, instructional, personal, time, and research. The top three words were social, media and doctoral. Each appeared 181, 177, and 115 times respectively. Words such as time and research appeared only 27 and 25 times respectively. The research team had anticipated the words, time and research, to appear more frequently. NVivo Pro 11 generated the data and word cloud charts below that demonstrate word frequency from the PtD posts analyzed for the research study.

Table 1. The 21 most frequently used words among doctoral students in the Facebook group, Path to Dissertation (PtD) from January 1, 2016, through October 31, 2016. Note. The data was generated using NVivo Pro 11.

\begin{tabular}{cccc}
\hline Word & Weighted Percentage & Count & Length \\
\hline social & $2.92 \%$ & 181 & 5 \\
media & $2.86 \%$ & 177 & 8 \\
doctoral & $1.86 \%$ & 115 & 7 \\
support & $1.29 \%$ & 80 & 8 \\
facebook & $0.90 \%$ & 56 & 5 \\
group & $0.87 \%$ & 54 & 9 \\
emotional & $0.82 \%$ & 51 & 12 \\
dissertation & $0.81 \%$ & 50 & 7 \\
explain & $0.77 \%$ & 48 & 7 \\
process & $0.68 \%$ & 42 & 7 \\
student & $0.63 \%$ & 39 & 8 \\
describe & $0.61 \%$ & 38 & 9 \\
education & $0.60 \%$ & 37 & 10 \\
networking & $0.55 \%$ & 34 & 7 \\
phoenix & $0.55 \%$ & 34 & 4 \\
used & $0.55 \%$ & 34 & 10 \\
university & $0.48 \%$ & 30 & 13 \\
instructional & $0.44 \%$ & 27 & 8 \\
personal & $0.44 \%$ & 27 & 4 \\
time & $0.44 \%$ & 27 & 8 \\
research & $0.40 \%$ & 25 & \\
\hline
\end{tabular}

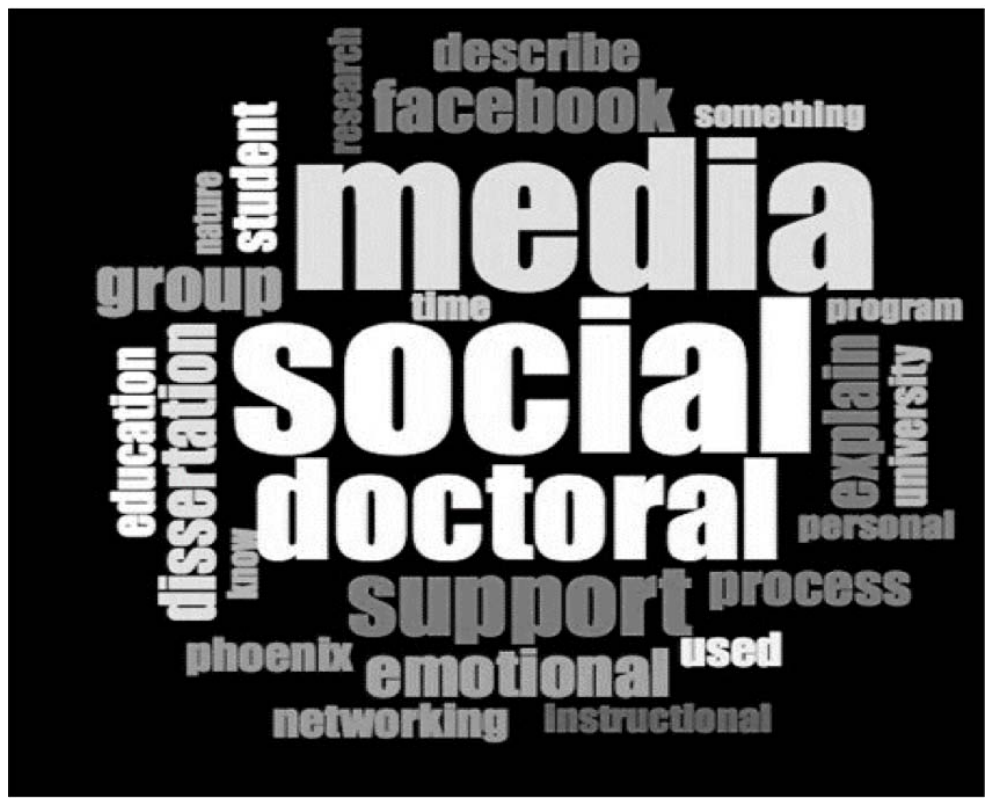

Figure 2. Word cloud of the most frequently used words among doctoral students in the Facebook group, Path to Dissertation (PtD) from January 1, 2016, through October 31, 2016. Created by NVivo Pro 11 (June 2017). 


\section{Results}

Iterative readings, discussions of the posts, and frequency counts indicated emerging themes. The themes included: study method and design, suggestions, recommendations, resources, systems and planning, research, encouragement, support, and alignment. The themes reveal that most students were in the group for one or both of two primary reasons. The first was to seek suggestions and recommendations on specific procedures and resources used in moving through the dissertation process. Doctoral students were looking for specific assistance with study methods, designs, and alignment with proposed research studies, including alignment to the degree program. The second reason was the desire for encouragement and support.

While the posts on Facebook provided information on what students talked about, the researchers found a need to analyze the posts further through interviews to determine why students use Facebook rather than the available classroom and university provided communications networks. To seek more profound and productive information, students that signed Informed Consents were interviewed to gather additional information. Each of the nine participants were divided among researchers and interviewed one-on-one. The participants' responses were coded and analyzed into NVivo 11. Twelve themes emerged: (a) proficiency in the use of social media, (b) influence of social media, (c) applications of social media, (d) descriptions of use, (e) purpose of use, (f) nature of use, (g) reason for rises, (h) trends of use, (i) changes of use, (j) description of topic, (k) value of education, and (l) additional comments that were relevant but not related to a specific topic. Three themes stood out: reasons for use, trends of use/changes in use, and educational value.

\section{Themes}

The reason for use. The most frequent reason why doctoral students used social media was learning, such as learning from peers who had similar experiences, learning about answers to difficult questions, learning the logistics of residencies, and learning from experts in the doctoral student's field of interest. One student reported explicitly learning about how to apply for various university approvals (QRM, IRB, and QRF). Some students reported using social media for emotional support or networking. One student reported getting more rapid feedback from colleagues on Facebook than from official advisors.

Trends of use and changes in use. Two closely related themes, trends of use and changes in use, revealed that students' level of use for social media increased or decreased multiple times. The use depended on the dissertation process or whether or not the students were having trouble moving forward. Trends of use were the events that were happening over which the student had no control yet caused the student to increase or decrease use of social media. Changes in technology, advancements in social media sites, changing requirements at the university, and being out of class were cited as reasons for increased use of social media while attempting to get a proposal accepted or a dissertation approved. One participant, as the driver for greater participation, cited being able to access Facebook and other social media with a smartphone, while two participants reported that the overall use stayed the same, but time spent on social media moved from personal and family interactions to interactions related to education. Four participants spoke about changes in use. Two of the doctoral students reported more use of social media during the doctoral process due to more significant opportunities to share and receive information such as research methods and designs. One participant reported that in the areas of research design, more time was spent researching scholarly articles, causing the amount of time available for social media to decline. The fourth student indicated that the amount of time dedicated to social media remained unchanged.

Educational value. Six of the nine participants reported that they found educational value in taking part in social media, such as the closed Facebook group. Three participants stated social media was more of a place to air frustrations and find like-minded individuals who understood the doctoral process. Participants, who reported educational value, found answers to questions more quickly on social media than going through the regular channels at the university that lead to finding many additional resources that related to dissertation topics and helped with the process. One participant reported that if the social media forum had not been available, many phone calls would have been placed to colleagues to get help when needed. Another participant reported that using social media helped with keeping up with the current information in the field of study and connecting with current leaders in the field.

\section{Results of the analysis (answers to research questions)}

To understand how doctoral students use social media to proceed through the doctoral process, findings were as follows:

- RQ. How are students using social media for communication?

Findings: Students use social media for communication in a variety of ways with support and direction from other students. 
- SQ1. How are doctoral students using social media and the relationships formed to avoid feelings of isolation and disconnectedness?

Findings: Student postings fell into three groups: (a) questions and answers about conducting research, (b) frustration/questions about the IRB process, and (c) celebrations with others.

- SQ2. How is social media helping students to proceed through their doctoral programs?

Findings: Social media helped some students complete the dissertation but did not help others due to: (a) varying degrees of student study and preparation, (b) information or answers that students may or may not have trusted, and (c) lack of understanding or completeness of some answers.

\section{Conclusions}

The purpose of the qualitative research study was to explore through a qualitative methodology and content analysis both the views and experiences of a group of doctoral students using a closed Facebook group. The twelve emerging themes from the research can aid educational leaders with useful information and insight into the effect of social media on doctoral students. The implications include how social media aids students in the completion of the doctoral degree, and how teachers and researchers can use or encourage doctoral students to use social media in PLNs.

\section{References}

Andrews, K. (2016). Correlation between mentors and learners perceptions of mentors' behaviors in completing online doctoral dissertations. Journal of Higher Education Theory and Practice, 16(2), 71-80. Retrieved from https://searchproquest-com.contentproxy.phoenix.edu/docview/1807473336?accountid=35812

Autry, M. K., \& Carter, M. (2015). Unblocking occluded genres in graduate writing: Thesis and dissertation support services at North Carolina State University. Composition Forum. Retrieved from http://compositionforum.com/archives.php

Babbie, E. (2013). The practice of social research. Wadsworth: Belmont, CA.

Bennett, L., \& Folley, S. (2014, May 26). A tale of two doctoral students: Social media tools and hybridised identities. Research in Learning Technology, 22(1). doi:10.3402/rlt.v22.23791

Bazeley, P., \& Jackson, K. (2013). Qualitative data analysis with NVIVO 11. Thousands Oaks, CA: SAGE.

Berger, R. (2015). Challenges and strategies in social work and social welfare PhD education: Helping candidates jump through the dissertation hoops. Journal of Teaching in Social Work, 35(1/2), 166-178. doi: $10.1080 / 08841233.2014 .973548$

Chenail, R. J. (2012). Conducting qualitative data analysis: Qualitative data analysis as a metaphoric process. The Qualitative Report, 17(1), 248. Retrieved from http://nsuworks.nova.edu/tqr/

De Argaez, E. (2017, July 10). World stats. Internet World Stats. Retrieved from http://www.internetworldstats.com/stats.htm

Greenwood, S., Perrin, A., \& Duggan, M. (2017). Social media update 2016. Pew Research Center: Internet, Science \& Tech. Retrieved from http://www.pewinternet.org/2016/11/11/social-media-update-2016/

Hamzah, M. H., Yusof, N., Kasim, A., Ngah, K., Mua, J., \& Zakaria, Z. (2013). NVivo 11 approach and content analysis in media flow analysis and alternative selected prime: Permatang pauh by-election. Asian Social Science, 9(15), 84. Retrieved from http://www.ccsenet.org/journal/index.php/ass

Harding-DeKam, J., Hamilton, B., \& Loyd, S. (2012). The hidden curriculum of doctoral advising. NACADA Journal, 32(2), 5-16. Retrieved from http://nacadajournal.org/?code=naaa-site

Hilscher, J. (2013). A case study examining how students make meaning out of using Facebook as a virtual learning community at a Midwestern university (Doctoral dissertation). Retrieved from Iowa State University.

Inman, A. G., \& Silverstein, M. E. (2003). Dissertation support group: To dissertate or not is the question. Journal of College Student Psychotherapy, 17(3), 59. Retrieved from http://www.tandfonline.com/loi/wcsp20

Kaufhold, K. (2017). Tracing interacting literacy practices in master's dissertation writing. London Review of Education, 15(1), 73-84. doi:10.18546/LRE.15.1.07

Kuckartz, U. (2014). Qualitative text analysis: A guide to methods, practice \& using software. London: SAGE. http://dx.doi.org/10.4135/9781446288719

Lindsay, S. (2015). What works for doctoral students in completing their thesis? Teaching In Higher Education, 20(2), 183-196. doi:10.1080/13562517.2014.974025

Martindale, T., \& Dowdy, M. (2010). Personal learning environments. In G. Veletsianos (Ed.) Emerging Technologies in Distance Education (pp. 177-193). Edmonton Alberta Canada: Athabasca University Press.

Mayring, P. (2000) Qualitative content analysis: Theoretical foundation, basic procedures, and software solution. FQS Forum: Qualitative Social Research, 1(2). http://dx.doi.org.10.17169/fqs 1.2.1089 
Merriam, S.B., \& Tisdell, E.J. (2016). Qualitative research: A guide to design and implementation. San Francisco, California: Jossey-Bass, A Wiley Brand.

Path to Dissertation Facebook Page (2016). Retrieved from https://www.facebook.com/groups/121396684546463/

QSR International (2017). NVivo Pro 11. Retrieved from http://www.qsrinternational.com/nvivo/free-nvivo-resources

Sanou, B. (2017). ICT facts and figures 2017. International telecommunications union. Geneva.

Saldana, J. (2016). The coding manual for qualitative researchers (3rd ed.). Los Angeles: SAGE.

Salmons, J. (2016). Doing qualitative research online. London: SAGE.

Satariyan, A., Getenet, S., Gube, J., \& Muhammad, Y. (2015). Exploring Supervisory Support in an Australian University: Perspectives of Doctoral Students in an Education Faculty. Journal of the Australian \& New Zealand Student Services Association, (46), 1-12. Retrieved from https://janzssa.scholasticahq.com/

Suny-Levin Institute. (2013). Globalization101.org: Technology and globalization. Retrieved from http://www.globalization101.org/uploads/File/Technology/tech.pdf

Zuber-Skerritt, O. (2015). Participatory action learning and action research (PALAR) for community engagement: A theoretical framework. Educational Research for Social Change, 4(1), 5. Retrieved from http://ersc.nmmu.ac.za/ 